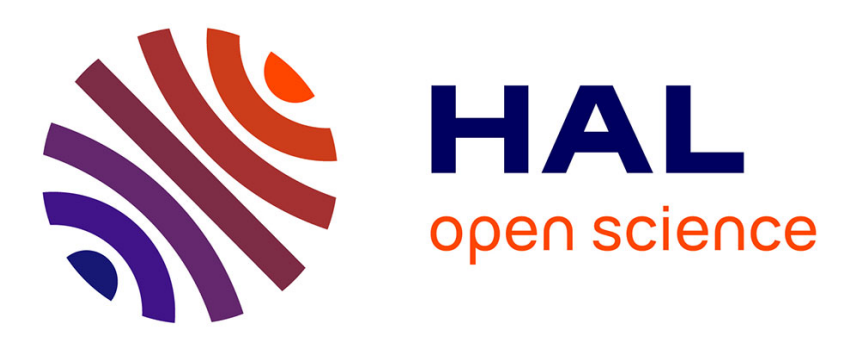

\title{
Phonological abstraction before lexical access: New evidence from rime priming
}

\author{
Sophie Dufour, Lucie Fléchard, Noël Nguyen
}

\section{To cite this version:}

Sophie Dufour, Lucie Fléchard, Noël Nguyen. Phonological abstraction before lexical access: New evidence from rime priming. Quarterly Journal of Experimental Psychology, 2022, 75 (12), pp.22112218. 10.1177/17470218221077917 . hal-03538147

\section{HAL Id: hal-03538147 \\ https://hal.science/hal-03538147}

Submitted on 7 Feb 2022

HAL is a multi-disciplinary open access archive for the deposit and dissemination of scientific research documents, whether they are published or not. The documents may come from teaching and research institutions in France or abroad, or from public or private research centers.
L'archive ouverte pluridisciplinaire HAL, est destinée au dépôt et à la diffusion de documents scientifiques de niveau recherche, publiés ou non, émanant des établissements d'enseignement et de recherche français ou étrangers, des laboratoires publics ou privés. 
Phonological abstraction before lexical access:

New evidence from rime priming

Sophie Dufour ${ }^{1,2}$ Lucie Fléchard $^{1}$ and Noël Nguyen ${ }^{1,2}$

1. Aix-Marseille Université, CNRS, LPL, UMR 7309, 13100 Aix-en-Provence, France

2. Institute for Language, Communication, and the Brain, Aix-Marseille Université, Aix-enProvence, France

Sophie Dufour

Laboratoire Parole et Langage

Aix-Marseille Université, CNRS

5, avenue Pasteur

13604 Aix-en-Provence

France Email: sophie.dufour@1pl-aix.fr 
Abstract: In this study, we focused on the rime priming effect and examined whether the frequency of rimes influences the size of the effect. Using the lexical decision task, we observed that the rime priming effect interacted with rime frequency with a stronger priming effect when the target words contained low-frequency rimes, in comparison to target words containing high-frequency rimes. Moreover, for both target words with low- and highfrequency rimes, a priming effect of similar magnitude was observed whether the primes and targets were pronounced by the same speaker or by different speakers. All together, these findings provide additional support for all the studies that plead for the existence of prelexical units and, in a more general way, for phonological abstraction prior to lexical access.

Keywords: Spoken-word recognition, rime priming, prelexical processing, phonological abstraction. 
A longstanding debate in the modeling of spoken word recognition is whether abstract prelexical units are extracted from the speech signal prior to lexical access (e.g. Bowers et al., 2016; Kazanina et al., 2018; McQueen et al., 2006; Mitterer et al., 2013). In the wellestablished view of spoken word recognition, and in particular in the so-called abstractionist models, the answer to this question is unambiguously positive. In this kind of models, the listeners first convert the speech signal into a sequence of discrete segments, which may, for instance, be features (Gaskell \& Marslen-Wilson, 1997), phonemes (Marslen-Wilson and Welsh, 1978; Norris, 1994), features and phonemes (McClelland \& Elman, 1986), or syllables (Mehler, 1981), and then project the output of this initial analysis onto lexical representations which are specified in terms of those abstract prelexical units. An alternative view, represented by exemplars models (Goldinger, 1998; Hawkins, 2003, Port, 2010) questions the existence of prelexical units mediating the mapping between the acoustic signal and the mental lexicon. In these models, all encountered instances or exemplars of words are stored in memory with their acoustic details, and word recognition entails a direct comparison of the current input in all its details with the acoustically detailed lexical representations.

In the present study, we focused on the rime priming effect that has been mostly explained in reference to abstractionist models, and taken as evidence that units smaller than the word, and here the rime, play a role during spoken word recognition. The rime priming has systematically produced facilitation effect, that is faster responses to LAMP after RAMP than after PINK in a variety of tasks: identification in noise (Slowiaczek et al., 1987), lexical decision (McQueen \& Sereno, 2005; Monsell \& Hirsh, 1998; Norris et al., 2002; Radeau et al., 1994; 1995; 1998; Slowiaczek et al., 2000; Spinelli et al., 2001), and shadowing (Dumay et al., 2001; Norris et al., 2002; Radeau et al.,1994;1995; Slowiaczek et al., 2000). Note that most of studies interested in pre-lexical phonological priming effects have manipulated the 
rime, because it is with this kind of units that strong and robust priming effects have been observed. For example, in a shadowing task, Radeau (1995) manipulated the amount of final overlap between primes and targets. The prime-target pairs shared one (FLEMME-TRAME), two (FLAMME-TRAME), or three (GRAMME-TRAME) phonemes from the end. She observed facilitation for rime overlap (FLAMME-TRAME) but no increase in the effect when the overlap included the consonant of the onset in addition to the rime (GRAMME-TRAME). When primes and targets shared only the last consonant (FLEMME-TRAME), no effect was found. In a more recent study using the shadowing task and controlling for the amount of overlap, Slowiaczek et al. (2000) obtained a greater facilitation effect when primes and targets shared the rime (RANK-BANK) than when they did not share it (HONKED-BANKED). The rime priming effect has been interpreted as reflecting the repeated activation of the same prelexical units during prime and target processing.

In accordance with this claim, the rime priming effect has important components that suggest that it relies on the activation of representations at a prelexical level of processing. First, it has been shown to be modality dependent. The effect is observed only when both the prime and the target are presented auditorily, and it dissipates under crossmodal presentation either when the prime is spoken and the target is visual (Radeau et al., 1994; Spinelli et al., 2001), or the reverse (Dumay et al., 2001). Second, the size of the priming effect does not vary as a function of the relative frequency of the primes and the targets. Similar effects were found for word targets of lower frequency than the primes and for word targets of higher frequency than the primes (Radeau et al., 1995). Finally, the rime priming effect does not depend on the lexical status of the primes and the targets. Similar effects were found whether the primes were words or nonwords (Slowiaczek et al., 2000; Spinelli et al., 2001). Also, similar effects were observed for word and nonword targets (Dumay et al., 2001; Norris et al., 
2002). The observation that final overlap facilitation does not vary as a function of primetarget frequency and target lexicality clearly suggests that the effect cannot be explained by activation of lexical representations. Indeed, if this was the case, greater facilitation should have been observed for word targets than for nonword targets because, by definition, nonwords have no lexical representations. Moreover, because word frequency necessarily operates at the level of lexical representations, a modulation of the effect as a function of prime-target frequency should have been observed. Hence, final overlap facilitation appears to have a prelexical locus and reflects the extraction of prelexical units, which are then used to contact the mental lexicon. The processing of the target is thus facilitated because its recognition involves the use of prelexical units that were already activated during prime processing.

Although the prelexical locus of the rime priming effect is rather well-established, to the best of our knowledge, no studies have yet examined whether the effect is influenced by factors exclusively linked to the prelexical unit it implies. This is an important endeavor, because we think that the evidence for the locus on the riming priming effect will be richer and more complete, if we can demonstrate that prelexical factors affect the size of the effect. This was the aim of this study. In particular, we manipulated rime frequency, and we therefore examined whether the prelexical rime priming effect varies as a function of the frequency of the prelexical rime units. As part of our aim to anchor the rime priming effect in abstractionist theories, we also examined whether this effect is sensitive to a talker change between the prime and the target words. Indeed, within abstractionist models, it is no matter if the primes and the targets are pronounced by different speakers and thus are acoustically more distant than if pronounced by the same speaker, because they are abstract units that mediate spoken word recognition. 


\section{Method}

Participants: Forty-eight French speakers between 18 and 23 years old from the University of Aix-Marseille participated in the experiment. All participants reported having no hearing or speech disorders. Each of them gave written informed consent prior to experimentation, and all received a course credit in exchange to their participation.

Materials: Forty eight monosyllabic target words, with a CVC syllabic structure, were selected from Vocolex, a lexical database for the French language (Dufour et al., 2002). All words had their uniqueness point - the phonemic position at which a word can be reliably identified - after their last phoneme. Twenty-four had a rime of low frequency, and the remaining 24 target words had a rime of high frequency. Rime frequency was calculated in two ways. The first measure consisted in counting the number of CVC words that shared the VC rime with the target words. The second measure was taken from the Diphones-fr database (New \& Spinelli, 2013), and consisted in counting all the words, whatever their length, that shared the VC rime with the target words. The number of occurrences was in average 1.29 (ranges: 0-2) and 12.96 (ranges: 1-32) on the first and second measure for the low-frequency rimes, and 11.29 (ranges: 9-18) and 334.88 (ranges: 41-1535) on the first and second measure for the high-frequency rimes. For each target word (e.g. CHUTE / fyt/ "falling"), two nonword primes with a CVC syllabic structure were created. One shared the VC rime with the target (e.g. /dyt/), and the other, used as control, shared no phoneme with the target (e.g. $/ \mathrm{mid} /$ ). Nonword primes were used because, especially for low-frequency rimes, it was difficult to find pairs of familiar words that rhymed. Also, each rime was used only once. Both sets of target words were matched for word frequency, with a mean frequency of 93 and 102 
occurrences per million, for the low- and high- frequency rime conditions, respectively. The target words and their related and control primes are provided in the Appendix.

The nonword primes were recorded by a male and a female native speaker of French, and the target words were recorded by the male speaker only. The recordings were made in a sound-attenuated room, and digitized at a sampling rate of $44 \mathrm{kHz}$ with 16-bit analog to digital recording. The average durations of the target words were 585 and $532 \mathrm{~ms}$ for the lowand high-frequency rime conditions, respectively. In the low-frequency rime condition, the average durations of the control and related primes were 558 and $552 \mathrm{~ms}$ respectively for the male speaker, and 577 and $585 \mathrm{~ms}$ respectively for the female speaker. In the high-frequency rime condition, the corresponding respective values were 553 and $557 \mathrm{~ms}$ for the male speaker, and 582 and $590 \mathrm{~ms}$ for the female speaker.

Because each target word was paired with two different nonword primes (related and control), and no participant was presented with the same target twice, two experimental lists were created. Each list included the 48 target words -24 with a low-frequency rime and 24 with a high-frequency rime. Half of the words with a low-frequency rime were preceded by the related primes and the other half by the control primes. Also, half of the words with a high-frequency rime were preceded by the related primes and the other half by the control primes. The lists were counterbalanced so that each target was preceded by the two types of nonword prime. Within each list, the target words were always heard as produced by the male speaker. In each frequency condition, half of the control and related nonword primes were heard as produced by the male speaker (i.e., same speaker condition), and the other half were heard as produced by the female speaker (i.e., different speaker condition). The two lists were 
then divided in two sub-lists so that each of the prime was heard as produced by the female speaker in one sub-list and by the male speaker in the other sub-list. For the purpose of the lexical decision task, 48 nonwords serving as targets were added to each list, and were constructed by changing the last phoneme of words not used in the test materials (e.g., /vam/ from vanne /van/ "valve"). So that the nonwords mimicked the target words, half of the target nonwords were preceded by a nonword prime sharing the rime (e.g., /pam/-/vam/) and the other half by an unrelated nonword prime (e.g. /luf/-/ $\mathrm{ad} /$ from châle "shawl"). Finally, to achieve a low proportion (20\%) of rime prime-target pairs, 144 filler trials without any relation between the primes and the targets were added to each list. Also, half of the filler trials consisted in nonword prime and target word pairs (e.g., /kin/-VACHE /va // "cow") and the other half consisted in nonword prime and target nonword pairs (e.g. /vaf/-/lin/).

Procedure. The participants were tested individually in a quiet room. Stimulus presentation and recording of the data were controlled by a PC running the E-Prime software (version 2.0, Psychology Software Tools). The primes and the targets were presented over headphones at a comfortable sound level. A $20 \mathrm{~ms}$ ISI separated the offset of the prime and the onset of the target. Participants were asked to make a lexical decision as quickly and accurately as possible on the target stimuli with "word" responses being made using their dominant hand on an E-Prime response box placed in front of them. RTs were recorded from the onset of targets. The prime-target pairs were presented randomly, and an inter-trial interval of $2000 \mathrm{~ms}$ elapsed between the participant's response and the presentation of the next stimulus. Participants were tested on only one experimental list and began the experiment with 12 practice trials. 


\section{Results}

One target word with a high-frequency rime that gave rise to an error rate of 54\% was removed. The mean RT and percentage of correct responses on target words in each condition are presented in Figure 1.

$<$ Insert Figure 1 about here $>$

RTs to target words were analyzed using linear mixed effects models with participants and items as crossed random factors, using the R software (R Development Core Team, 2016) and the lme4 package (Baayen et al., 2008; Bates and Sarkar, 2007). The RT analysis was performed on correct responses, thus removing 205 (9.09\%) data points out of 2256. Two RTs $<500 \mathrm{~ms}$ and six RTs $>3000 \mathrm{~ms}$ were considered as outliers (less than 1\%) and were also excluded from the analysis. For the model to meet the assumptions of normally-distributed residuals and homogeneity of variance, a log transformation was applied to the RTs (Baayen \& Milin, 2010) prior to running the model. The model was run on 2043 data points. We tested a model with the variables prime type (related, control), rime frequency (low, high), speaker (same, different) and their interaction entered as fixed effects. The model included participants and items as random intercepts, plus random participant slopes for the withinparticipant factors prime type, rime frequency and speaker, and item slopes for the withinitem factors prime type and speaker (see Barr et al., 2013). We applied a contrast coding for the independent variables, namely -0.5 for one condition and 0.5 for the other condition, which allows an estimation of the global effects. Global effects were reported and were obtained using the Anova function from the Car R package. 
The model revealed a significant rime priming effect with RTs on target words shorter when preceded by related nonword primes in comparison to control nonword primes $\left(\chi^{2}(1)=\right.$ 41.06, $p<.001)$. Crucially, the model also revealed a significant interaction between prime type and frequency $\left(\chi^{2}(1)=6.78, p<.01\right)$. This interaction was due to a stronger priming effect for words with low-frequency rimes than for word with high-frequency rimes. Subsequent comparisons indicated that the rime priming effect was significant in both the low-frequency $(\mathrm{z}=7.56 ; p<.001)$ and high-frequency $(\mathrm{z}=3.15 ; p<.01)$ rime condition. No other effects were significant.

The percentage of correct responses was analyzed using a mixed-effects logit model (Jaeger, 2008) following the same procedure as for RTs. No significant effects were found. 


\section{General Discussion}

Numerous studies have shown facilitation of processing when an auditory target word is preceded by another auditory stimulus sharing with the target the final phonemes and, in particular, the rime (e.g., Dumay et al., 2001; Norris et al., 2002; Radeau et al., 1995; Slowiaczek et al., 2000; Spinelli et al., 2001). This rime priming effect has been largely interpreted within abstractionist models of spoken word recognition that assume an intermediate prelexical level of processing between the acoustic input and the mental lexicon. Within this kind of models, the rime priming effect arises because the same prelexical representations that are activated during prime processing are re-used during target processing. Considering that abstractionist theories are the best suited to account for the rime priming effect, we examined whether this priming effect is influenced by the frequency of the prelexical units that it implies. Using the lexical decision task, we showed that the rime priming effect interacted with rime frequency with a stronger priming effect when the target words were composed of low-frequency rimes, in comparison to target words composed of high-frequency rimes. To our knowledge, this finding constitutes the first demonstration of an influence of rime frequency on the size of the rime priming effect. Our study thus provides new and additional evidence for the involvement of prelexical units in the rime priming effect, and in a more general way, for the assumption that units smaller than the words are extracted from the speech signal during spoken word recognition. Moreover, we showed that the rime priming effect is independent of a talker change between the primes and the targets. As a result, for both target words with low- and high-frequency rimes, a priming effect of similar magnitude was observed whether the primes and targets were pronounced by the same speaker or by different speakers. Undoubtedly, such a result strengthens the claim that abstract prelexical units are used during spoken word recognition. 
Although we clearly showed that rime frequency is an important factor in determining the magnitude of the rime priming effect, it remains however to explain why a stronger priming effect was observed for target words composed of low-frequency rimes. Stronger priming effect for prelexical units of low frequency was already observed in visual word recognition studies. For example, Grainger and Jacob (1993) manipulated the positional frequencies of letters shared by the primes and targets in masked partial-word priming experiments, and reported that the lower the positional frequency of letter is, the stronger the resulting facilitation is. One possibility is that we have captured a general and well-known phenomenon that participants benefit from priming to a greater extent in more difficult conditions than in easier conditions. Because low-frequency items, by definition, are processed less fluently than high-frequency items, the increment in fluency due to prior exposure is proportionally greater for low-frequency than for high-frequency items. Another possibility is that the stronger priming effect for low-frequency rimes reflects the interactive dynamics between the lexical and prelexical level of processing. Indeed, although past studies and this study concur in showing that prelexical units are involved in the rime priming effect, this does not mean that the effect uniquely arises at the prelexical level of processing. In interactive activation models such as TRACE, activated prelexical units pass their activation to lexical representations that contain them, and these activated lexical representations compete between them for recognition, via lateral inhibition. Another component of the TRACE model is that it includes top-down connections between lexical and prelexical units, by which lexical representations, once activated, boost the activation level of their prelexical units. Within this kind of framework, since the number of words that share a particular rime is necessary greater for primes containing high-frequency rimes than for primes containing lowfrequency rimes, primes with high-frequency rimes should activate more lexical candidates than do primes with low-frequency rimes. As a result, lexical competition should be more 
intense when high-frequency rimes are in play, which has for consequence to reduce the boost that prelexical units receive from the lexical level, thus accounting for the smaller priming effect for target words composed of high-frequency rimes. We acknowledge however that such an account should also predict an influence of word frequency on the rime priming effect. High-frequency words receiving more activation than low-frequency words, they should in turn send more activation on their prelexical units than low-frequency words, and thus stronger rime priming for high-frequency words is expected. This was however not the case in the only study (Radeau et al., 1995) that manipulated the relative prime-target frequency and that failed to report an influence of this variable on the size of the rime priming effect. One way to reconcile these studies is to envisage several loci to the rime priming effect, a purely prelexical locus with an effect arising from the repeated activation of the same prelexical units during prime and target processing, and an effect arising from top-down connections between the lexical and prelexical levels. The implication of the lexical level in the rime priming effect would depend on the amount of competition generated at the lexical level, with an effect impacted by interactions between the lexical and prelexical level when numerous lexical representations are activated, and thus in case of stimuli composed of highfrequency rimes.

Whatever the precise mechanism by which rime frequency influences the magnitude of the rime priming effect, our study constitutes another demonstration for the existence of prelexical units. It is important to underline that we reported evidence in favor of the use of prelexical units even though the task of the participants did not relate to a particular prelexical units, as this is the case in tasks like phoneme, syllable or rime detection in which participants can use these sublexical units only for the need of the task. Automatic prelexical abstraction has been also demonstrated in several perceptual learning experiments (e.g. McQueen et al., 
2006; Mitterer et al., 2013). In this kind of experiment, it is observed that participants categorize an ambiguous fricative between [f] and [s] as [f] when they have been previously exposed to stimuli in which the ambiguous phoneme replace the [f] in [f]-final words, and as [s] when they have been previously exposed to stimuli in which the ambiguous phoneme replace the $[\mathrm{s}]$ in $[\mathrm{s}]$-final words. Such a finding thus suggests that listeners use lexical knowledge to retune speech-sound perception. Crucially, it has been shown that this adjustment in sound perception generalizes to words to which participants have not been previously exposed. This generalization across words suggests that the retuning occurs prelexically, and entails sublexical phonological abstraction. Hence, our study provides additional support for all these studies that plead for the existence of prelexical units, and in a more general way for phonological abstraction prior to lexical access.

In a more general way, our study provides new evidence that abstract prelexical units contribute to spoken word recognition, and adds to the old but still current debate regarding the necessity of an intermediate level of processing between the acoustic signal and the mental lexicon (e.g. Bowers et al., 2016; Kazanina et al., 2018; McQueen et al., 2006; Mitterer et al., 2013). Although the existence of linguistic units (Samuel, 2020) has been recently questioned, our study indicates that the phoneme and here combination of phonemes (i.e. the rime) contribute to spoken word recognition. Note that the observation that the rime contributes to pre-lexical processing is fully compatible with a recent model of spoken word recognition, the TISK model (Hannagan et al., 2013; You \& Magnuson, 2018), which incorporates a set of diphone units that code the order of phonemes, and a set of positionindependent phoneme units. Although there is recent evidence for the existence of positionindependent phoneme units coming from studies showing transposed-phoneme effects at least when consonants are transposed (e.g. Dufour \& Grainger, 2019; Gregg et al., 2019; Toscano 
et al., 2013), the rime priming effect could be compatible with the view that position/contextdependent units (i.e., allophones; Mitterer et al., 2018) rather than position-independent units (i.e., phonemes) contribute to spoken word recognition. Indeed, the rime units could be viewed as combinations of position-dependent phoneme units, since the same phonemes at the same positions are share by the primes and the targets. However, the position/contextdependent unit account strongly depends on precisely how allophones are defined. In our case, since the rime units are composed of phonemes that pronounce in the same way in the primes and in the targets, the rime priming effect could be due to the phonetic similarity between the phonemes' allophonic surface forms in the rimes of both the prime and target. If that was the case, one could predict that a greater overlap between these allophonic forms in the prime's and target's rimes should be associated with a larger rime priming effect. However, under this assumption, the rime priming effect should have been stronger when the primes and the targets were pronounced by the same speaker compared with different speakers. This is not what we observed, since the rime priming effect has proven to be insensitive to a change in the speaker between the primes and the targets.

To sum up, our study showed a clear influence of rime frequency on the magnitude of the rime priming effect, with words composed of low-frequency rimes benefiting more from priming that words composed of high-frequency rimes. Hence, just as effects involving lexical representations have been shown to vary as a function of lexical factors, the rime priming effect for which the involvement of prelexical representations is well established varies as a function of a prelexical factor, namely the frequency of prelexical rime units. Moreover, the rime priming effect appeared to be insensitive to a talker change between the primes and the targets, thus arguing again for phonological abstraction before lexical access. Note that in this study, we focused on the rime to examine pre-lexical priming effects because 
it is with this kind of units that strong and robust priming effects have been observed. This could suggest that the rime is a phonologically relevant unit (see Slowiaczek et al., 2000). Further research could nonetheless be done in the field of spoken word recognition to examine pre-lexical priming effects with various combinations of phonemes that do not constitute rime units, and for instance whether pre-lexical priming effects could also be observed when the primes and the targets share two phonemes (e.g. FRAPPE-GRADE for French) in other position than in the final part of the speech signal. 


\section{References}

Baayen, R. H., Davidson, D. J., \& Bates, D. M. (2008). Mixed-effects modeling with crossed random effects for subjects and items. Journal of Memory and Language, 59, 390412.

Baayen, R. H., \& Milin, P. (2010). Analyzing reaction times. International Journal of Psychological Research, 3, 12-28.

Barr, D. J., Levy, R., Scheepers, C., \& Tily, H. J. (2013). Random effects structure for confirmatory hypothesis testing: Keep it maximal. Journal of Memory and Language, $68,255-278$.

Bates, D. M., \& Sarkar, D. (2007). lme4: Linear mixed-effects models using S4 classes, R package version 2.6, retrieved 20 November 2017 from http://lme4.r-forge.rproject.org/.

Bowers, J. S., Kazanina, N., \& Andermane, N. (2016). Spoken word identification involves accessing position invariant phoneme representations. Journal of Memory and Language, 87, 71-83.

Dufour, S., \& Grainger, J. (2019). Phoneme-order encoding during spoken word recognition: A priming investigation. Cognitive Science, 43, 1-16.

Dufour, S., Peereman, R., Pallier, C., \& Radeau, M. (2002). VoCoLex: A lexical database on phonological similarity between French words. L'Année Psychologique, 102, 725 746.

Dumay, N., Benraïss, A., Barriol, B., Colin, C., Radeau, M., \& Besson, M. (2001). Behavioral and electrophysiological study of phonological priming between bisyllabic spoken words. Journal of Cognitive Neuroscience, 13, 121-143.

Gaskell, M. G.,\&Marslen-Wilson,W. D. (1997). Integrating form and meaning: A distributed model of speech perception. Language and Cognitive Processes, 12, 613-656.

Goldinger, S. D. (1998). Echoes of echoes? An episodic theory of lexical access. Psychological Review, 105, 251-279.

Grainger, J., \& Jacobs, A. M. (1993). Masked partial-word priming in visual word recognition: Effects of positional letter frequency. Journal of Experimental Psychology: Human Perception and Performance, 19, 951-964. 
Gregg, J., Inhoff, A.W. \& Connine, C.M. (2019). Re (Re) re-considering the role of temporal order in spoken word recognition. Quarterly Journal of Experimental Psychology, 72, 2574-2583.

Hannagan, T., Magnuson, J. S., \& Grainger, J. (2013). Spoken word recognition without a TRACE. Frontiers in Psychology, 4, 563.

Hawkins, S. (2003). Roles and representations of systematic fine phonetic detail in speech understanding. Journal of Phonetics, 31, 373-405.

Jaeger, T. F. (2008). Categorical data analysis: Away from ANOVAs (transformation or not) and towards logit mixed models. Journal of Memory and Language, 59(?), 434-446.

Kazanina, N., Bowers, J. S., \& Idsardi, W. (2018). Phonemes: Lexical access and beyond. Psychonomic Bulletin and Review, 25, 560-585.

Marslen-Wilson, W. D., \& Welsh, A. (1978). Processing interaction and lexical access during word recognition in continuous speech. Cognitive Psychology, 10(?), 29-63.

McClelland, J. L., \& Elman, J. L. (1986). The TRACE model of speech perception. Cognitive Psychology, 18, 1-86.

McQueen, J. M., Cutler, A., \& Norris, D. (2006). Phonological abstraction in the mental lexicon. Cognitive Science, 30, 1113-1126.

McQueen, J. M., \& Sereno, J. (2005). Cleaving automatic processes from strategic biases in phonological priming. Memory \& Cognition, 33, 1185-1209.

Mehler, J. (1981). The role of syllables in speech processing: Infant and adult data. Philosophical Transactions of the Royal Society, Series B, 295, 333-352.

Mitterer, H., Reinisch, E., \& McQueen, J. M. (2018). Allophones, not phonemes in spokenword recognition. Journal of Memory and Language, 98, 77-92.

Mitterer, H., Scharenborg, O., \& McQueen, J.M. (2013). Phonological abstraction without phonemes in speech perception. Cognition, 129, 356-361.

Monsell, S., \& Hirsh, K. W. (1998). Competitor priming in spoken word recognition. Journal of Experimental Psychology: Learning, Memory, and Cognition, 24, 1495-1520.

New, B. \& Spinelli, E. (2013). Diphones-fr: A French database of diphones positional frequency. Behavior Research Methods 45. 758-764.

Norris, D. (1994). SHORTLIST: A connectionist model of continuous speech recognition. Cognition, 52, 189-234.

Norris, D., McQueen, J. M., \& Cutler, A. (2002). Bias effects in facilitatory phonological priming. Memory \& Cognition, 30, 399-411. 
Port, R. (2010). Rich memory and distributed phonology. Language Sciences, 32, 43-55.

R Development Core Team. (2016). R: A language and environment for statistical computing. R Foundation for Statistical Computing. Available from http://www.R-project.org

Radeau, M. (1995). Facilitatory and inhibitory phonological priming effects as a function of overlap position. Paper presented at the 36th annual meeting of the Psychonomic Society, Los Angeles, CA.

Radeau, M., Besson, M., Fonteneau, E., \& Castro, S. L. (1998). Semantic, repetition, and rime priming between spoken words: Behavioral and electrophysiological evidence. Biological Psychology, 48, 183-204.

Radeau, M., Morais, J., \& Segui, J. (1995). Phonological priming between monosyllabic spoken words. Journal of Experimental Psychology: Human Perception and Performance, 21, 1297-1311.

Radeau, M., Segui, J., \& Morais, J. (1994). The effect of overlap position in phonological priming between spoken words. In Proceedings of the International Conference on Spoken Language Processing (vol. 3, pp. 1419-1422). Yokohama, Japan: The Acoustical Society of Japan.

Samuel, A. G. (2020). Psycholinguists should resist the allure of linguistic units as perceptual units. Journal of Memory and Language, 111, 104070.

Slowiaczek, L. M., McQueen, J., Soltano, E. G., \& Lynch, M. (2000). Phonological representations in prelexical speech processing: Evidence from form-based priming. Journal of Memory and Language, 43, 530-560.

Slowiaczek, L. M., Nusbaum, H. C., \& Pisoni, D. B. (1987). Phonological priming in auditory word recognition. Journal of Experimental Psychology: Learning, Memory, and Cognition, 13, 64-75.

Spinelli, E., Segui, J., \& Radeau, M. (2001). Phonological priming in spoken word recognition with bisyllabic targets. Language and Cognitive Processes, 16, 367-392.

Toscano, J. C., Anderson, N. D., \& McMurray, B. (2013). Reconsidering the role of temporal order in spoken word recognition. Psychonomic Bulletin \& Review, 20, 981-987.

You, H. \& Magnuson, J. (2018). TISK 1.0: An easy-to-use Python implementation of the time-invariant string kernel model of spoken word recognition. Behavior Research Methods, 50, 871-889. 

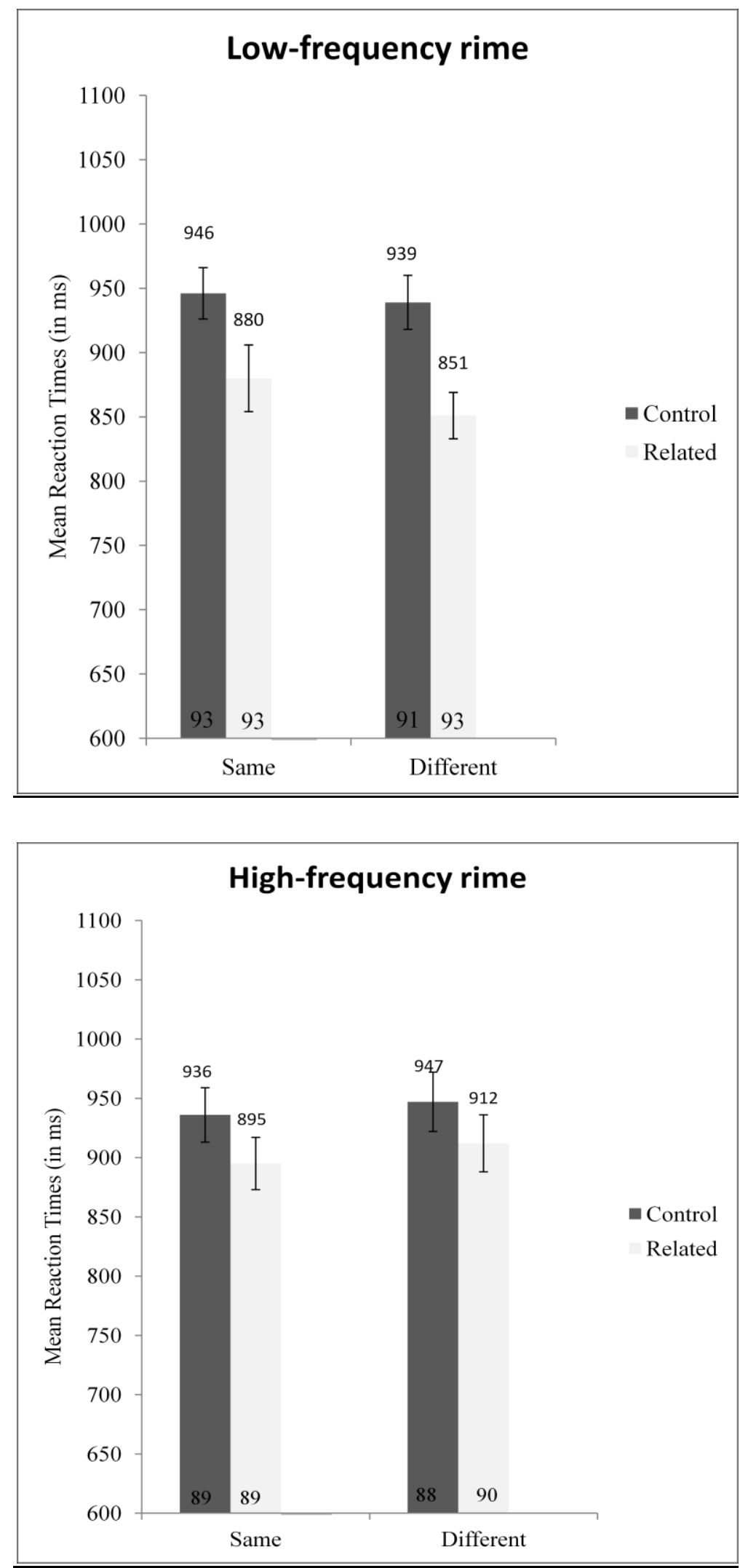
Figure 1: Mean Reaction Times (in ms) and Standard Errors for the control and related nonword primes in each of the speaker (same vs. different) and rime frequency (low vs. high) conditions. Percentages of correct responses are shown at the bottom of the graph.

Appendix: Nonword primes and target words used in the experiment.

\begin{tabular}{|c|c|c|c|c|c|}
\hline \multicolumn{3}{|c|}{ Low-frequency rime } & \multicolumn{3}{|c|}{ High-frequency rime } \\
\hline Control & Related & Target & Control & Related & Target \\
\hline beuve & bougue & fougue & mêpe & nar & char \\
\hline meuil & vinze & quinze & vuque & rerre & terre \\
\hline zague & juve & cuve & pinque & teine & veine \\
\hline kouge & pongue & longue & leuve & voule & poule \\
\hline toupe & penre & genre & pouc & nir & rire \\
\hline domte & rugue & fugue & guoupe & guatte & chatte \\
\hline vince & jube & cube & vuze & chote & note \\
\hline mupe & kymphe & lymphe & kige & poute & route \\
\hline teurre & pinge & linge & moupe & $\mathrm{kac}$ & lac \\
\hline zune & lompe & pompe & chêve & fal & bal \\
\hline souffe & chude & rude & vombe & chore & tort \\
\hline muc & bèffe & chef & chive & chette & dette \\
\hline tide & peune & jeune & rombe & zache & cache \\
\hline chigue & fanque & banque & chague & pime & lime \\
\hline chonce & feige & beige & saffe & chille & mille \\
\hline fuque & finde & dinde & puche & kente & vente \\
\hline chulle & chingue & dingue & jouf & vasse & tasse \\
\hline chune & fouze & douze & lousse & jaille & paille \\
\hline jave & roude & coude & jampe & zure & cure \\
\hline poce & pouve & louve & mide & dute & chute \\
\hline kousse & muge & luge & guande & guite & site \\
\hline pide & reige & neige & rule & vape & tape \\
\hline guse & beul & seul & pec & kisse & vis \\
\hline tèpe & mambe & jambe & neinte & mour & jour \\
\hline
\end{tabular}

